Effective triage in the Pacific region: the development and implementation of the Solomon Islands Triage Scale

Authors: Lynne E Wanefalea, BN, MNIC, Clinical Nurse Specialist, Clinical Lecturer, Skills and Simulation;

Rob Mitchell MBBS (Hons) BMedSc (Hons) MPH\&TM GradCertDisRefHlth, FACEM, Emergency Physician;

Dr Georgina Phillips, MBBS, FACEM;

Dr Trina Sale, Director of Emergency Medicine, Solomon Islands;

Elisabeth Sanau, RN.

All authors institutional Affiliation:

National Referral Hospital

P.O. Box 349, Honiara, Guadalcanal Province,

Solomon Islands.

Tel: +677 23600 .

Corresponding Author:

Mrs Lynne Wanefalea

59-61 Jacob Street

North Bendigo,

Vic, Australia, 3550

lynne.wanefalea@monash.edu

$\mathrm{m} / 0438957267$

Word count: 2694

This is the author manuscript accepted for publication and has undergone full peer review but has not been through the copyediting, typesetting, pagination and proofreading process, which may lead to differences between this version and the Version of Record. Please cite this article as doi: $10.1111 / 1742-6723.13248$

This article is protected by copyright. All rights reserved. 


\title{
Effective triage in the Pacific region: the development and implementation of the \\ Solomon Islands Triage Scale
}

\begin{abstract}
Lynne E Wanefalea, BN, MNIC, Clinical Nurse Specialist, Clinical Lecturer, Skills and Simulation; Rob Mitchell MBBS (Hons) BMedSc (Hons) MPH\&TM GradCertDisRefHlth, FACEM, Emergency Physician; Dr Georgina Phillips, MBBS, FACEM; Dr Trina Sale, Director of Emergency Medicine, Solomon Islands; Elisabeth Sanau, RN.
\end{abstract}

\begin{abstract}
The Emergency Department at the National Referral Hospital in Honiara, Solomon Islands receives approximately 50,000 patients per year. A 2014 review of ED functioning identified deficiencies in triage processes. Placement of Australian volunteer advisors provided an opportunity to develop and implement a purpose-designed triage system.
\end{abstract}

Methods

Action research methodology and the 'plan, act, observe, reflect' cycle was employed, leading to the development of a three-tier triage system based on the South African Triage Scale. ED patient flow and data management processes were simultaneously updated, and staff were trained in the new system.

After a pilot period, the Solomon Islands Triage Scale (SITS) was implemented in August 2017. Evaluation after three months of operation included predictive validity (using admission and case fatality rates as surrogate markers of urgency) and reliability (based on inter-rater agreement at retrospective chart review by an independent nurse).

This article is protected by copyright. All rights reserved. 
Results

In the period 1 August - 31 October there were 10,905 presentations, of which $97.1 \%$ were allocated a triage category ( $1 \%$ category $1,21.3 \%$ category 2 and the remainder category 3$)$. Admission rates correlated closely with triage category $(p=<0.01)$. The case fatality rate was $22.1 \%$ for category 1 patients, $0.09 \%$ for category 2 patients and $.01 \%$ for category 3 patients $(p=<0.01)$. An audit of 96 records conducted in October 2017 revealed $88.4 \%$ agreement for triage category allocation.

Conclusion

SITS is the first three-tier triage scale to be implemented in the Pacific region and appears to have adequate validity and reliability. The partnership between Australian volunteers and local clinicians is a positive example of capacity development and represents a model that could be implemented in other resource-limited settings.

\section{Background}

The Solomon Islands is a sovereign state in the Pacific Ocean with a population of approximately $600,000 .^{1}$ It comprises nine provinces and more than 900 islands. ${ }^{2}$ The country is ranked 156 on the United Nations Human Development Index, with a gross national income of US\$1,880 per capita. ${ }^{1,3}$

The Solomon Islands' health system is significantly under-resourced. Health system expenditure constitutes $5.4 \%$ of gross domestic product, and there is a critical shortage of health workers. ${ }^{2}$ The only referral hospital is located in the capital Honiara, a coastal city with a population of approximately 80,000 . Major health challenges include an escalating burden of non-communicable disease as well as ongoing communicable disease threats, such as malaria, dengue fever and tuberculosis. ${ }^{2}$

Emergency care in the Solomon Islands

This article is protected by copyright. All rights reserved. 
The Solomon Islands' sole established Emergency Department (ED) is at the National Referral Hospital (NRH). The department receives approximately 50,000 patients per year with an estimated admission rate of $15 \%$. It consists of three resuscitation bays, 17 acute adult beds, seven paediatric beds, two consulting rooms and a minor theatre. Total ED staff comprises two consultant emergency physicians, around 10 junior doctors and approximately 50 nurses.

In response to perceived shortcomings in the quality of emergency care delivered at $\mathrm{NRH}$, the Solomon Islands Government requested Australian Government assistance to improve ED functioning. The Department of Foreign Affairs and Trade (DFAT) subsequently commissioned the Australasian College for Emergency Medicine (ACEM) to conduct a scoping mission to assess emergency care (EC) capacity and inform future development projects. The review, led by an Australian emergency physician (GP), identified a large number of issues including inadequate staffing, overcrowding and access block. It also highlighted major deficiencies in the ED's triage system, including long delays, limited equipment and infrastructure, the lack of a functional triage scale, a paucity of trained staff, poor documentation and ineffective streaming. ${ }^{4}$

The scoping mission precipitated a DFAT-funded ED quality improvement program delivered by ACEM and AVI. This provided funding for several Australian volunteer positions including an emergency consultant advisor, emergency senior registrar and nurse advisor. Triage, patient flow and access block were identified as priority areas.

\section{Triage in developing settings}

The lack of a functional ED triage system is not unique to the Solomon Islands. Globally, most people do not have access to timely and effective emergency care. ${ }^{5,6}$ EC has not featured highly on global development agendas, despite its potential to positively impact on preventable morbidity and mortality. $5,7,8$

Triage aims to sort patients based on the urgency of their condition, and is essential whenever there is a mismatch between demand for EC and resource availability. ${ }^{9}$ While the role of triage is firmly established in 
mature EC systems, there is limited evidence regarding the value and efficacy in low- and middle-income countries (LMICs). ${ }^{9,10}$

A number of triage scales have been developed for resource-limited environments (RLEs). The most widely studied is the South African Triage Scale (SATS), which has shown acceptable validity and reliability in several settings. ${ }^{10-17}$ One Malawian study has demonstrated that training staff in emergency skills, introducing triage and improving patient flow can reduce mortality rates and increase efficiency. ${ }^{18}$ Although this data is not definitive, it suggests that implementation of triage systems in RLEs has the potential to improve clinical outcomes as well as ED functioning.

Improving triage at the National Referral Hospital

The arrival of volunteer advisors to NRH ED in June 2016 (LW) and February 2017 (RM) provided an opportunity to reform triage processes at $\mathrm{NRH}$. In consultation with local clinician leaders (TS and ES) and the broader ED staff, a process to develop and implement the Solomon Islands Triage Scale (SITS) was established. From the outset, the project aimed to enhance triage capacity while simultaneously improving patient flow and data management.

\section{Methods}

The approach to triage reform at NRH utilised action research methodology and the 'plan, act, observe and reflect' cycle. ${ }^{19}$ Ethics approval was not required as the intervention met quality improvement criteria.

Plan

Following review of the literature, observation of existing ED processes and consultation with local staff, SATS was identified as the most appropriate triage instrument. In order to contextualise it to the NRH setting and minimise complexity, the tool was adjusted from four to three tiers, and the Triage Early Warning Score (TEWS) component was removed.

This article is protected by copyright. All rights reserved. 
In recognition of the need for tailored triage processes for paediatric patients, ${ }^{20}$ elements of the World Health Organization (WHO) paediatric triage model were incorporated for the paediatric SITS algorithm. A mid upper arm circumference (MUAC) measurement was also included as a malnutrition screening tool.

A new triage and registration form was developed along with a revised patient flow pathway that accounted for the physical limitations of the ED (Figure 1). A variety of instructional posters were also produced, including triage algorithms for adult (Figure 2a) and paediatric patients (Figure $\mathbf{2 b}$ ). In order to counter the removal of the TEWS, age-appropriate, colour-coded observation charts indicating escalation criteria were also introduced.

Simple clipboards and wooden containers facilitated the new system. A new triage station was built with donated funds, and all staff were provided an opportunity to purchase a subsidised patient assessment pack including a sphygmomanometer, stethoscope and temperature probe.

Several adult acute beds were quarantined for short stay admissions with the aim of optimising patient flow. The ED also implemented a new data management process utilising Microsoft Excel, whereby the administration officer collected patient triage forms and retrospectively entered data into the ED's sole computer. The database was designed to capture key time points during a patient's journey so that sources of delay could be identified.

\section{Act and observe}

In preparation for the new system, triage training was delivered to all ED nurses with sufficient experience. This included clinical scenarios and opportunities to practice using the new form. Simultaneously, doctors were 
given information sessions on the new triage system and reformed ED processes. A presentation at 'Grand Rounds' was also undertaken to educate non-ED staff about SITS. At the completion of the education program, nursing rosters were amended to allocate competent staff to triage shifts. An article was also published in the local newspaper about the new system.

Experienced nurses who understood the new system and could facilitate flow through the ED were allocated to a new 'patient flow manager' (PFM) role. In addition to flow management, the PFM was also responsible for triaging non-ambulatory patients who presented via ambulance or private vehicle (as this entry was not visible from the triage desk) and re-assessing deteriorating patients in the internal waiting room.

SITS was implemented in May 2017 with a plan to pilot the new system over a three-month period. In the first month of operation, Australian volunteers were heavily involved in its operation. Thereafter, oversight was provided by local clinicians but with the support of LW and RM.

Regular team meetings were held throughout the pilot period to identify areas for refinement. After three months of operation, minor adjustments were made to the triage form, flow pathway and database. Maintenance of the new system was handed over to local clinician leaders in August 2017, with ongoing support provided remotely by Australian volunteer advisors.

\section{Reflect}

The first formal assessment of SITS functioning was undertaken in October 2017. This aimed to review ED performance (including waiting times) in light of the new system; describe the urgency of the patient cohort using SITS categories; and evaluate the validity and reliability of the triage instrument. 
Reliability refers to the extent to which repeated assessments of the same patient yield the same result, whereas validity refers to the ability of the instrument to reflect the true urgency of the patient's condition. ${ }^{21}$ Of the various types of validity evaluation, criterion validity (ie, performance against an objective measure) is the purist, but is challenging to assess with triage systems because there is no gold standard marker of urgency. For this reason, surrogate measures are commonly used to assess predictive validity (the relationship between triage score and clinical outcomes) and consensual validity (the extent to which a tool is accepted and adopted).

The preliminary evaluation of SITS incorporated two components: a review of prospectively collected data entered into the new ED database (for August to October) and an audit of triage records. The database review was intended to describe the patient cohort and assess predictive validity using admission rate and case fatality rates (for deaths in the ED) as surrogate markers of urgency. This approach has been used widely in triage research. ${ }^{11}$

The audit was conducted during a one-week support visit to NRH ED in October 2017. A sample size calculation, based on a total population of 120 (the approximate number of daily presentations), determined that at least 91 charts would need to be audited to achieve a confidence interval of $+/-5 \%$ at a confidence level of $95 \%$. A convenience sample of charts was reviewed by an independent Australian triage nurse, who separately allocated a triage category to each presentation based on the recorded clinical information. This nurse was blinded to the original triage categorisation.

Data analysis was generally limited to descriptive statistics. Differences in admission and case fatality rates between triage categories (predictive validity) were assessed using Chi-square for independence, and interrater reliability was measured using percent agreement. All data were analysed using Microsoft Excel. 


\section{Results}

Patient cohort

In the period 1 August - 31 October there were 10,905 presentations (an average of 118.5 per day), of which $60.8 \%$ were adults. Overall, $97.1 \%$ of patients were allocated a triage category; $1 \%$ were assigned a category 1 , $21.3 \%$ category 2 and the remainder category 3.

Triage registration data revealed that a large number of patients were presenting with non-urgent issues. For instance, $5.8 \%$ of patients were scheduled returns (reviews) and $2.2 \%$ presented only for a repeat prescription.

The average waiting time (triage to being seen by a doctor) was 94 minutes for category 1 patients, 195 minutes for category 2 patients and 232 minutes for category 3 patients. These figures are likely to overestimate the time-to-being-seen because of incomplete and inaccurate data recording by treating doctors.

As evidence of the ongoing challenges with access block, the average ED length of stay for 25 hours for all admitted patients and 38.8 hours for medical patients.

Predictive validity

As displayed in Figure 3, there were significant differences in admission rates between triage categories $(p=<0.01)$. The overall admission rate is likely to be higher because disposition data were recorded for only $75 \%$ of patients.

This article is protected by copyright. All rights reserved. 
Over the 3-month study period, the vast majority of ED deaths occurred in category 1 patients (27/30 deaths, 90\%). The case fatality rate was $22.1 \%$ (27/95) for category 1 patients, $0.09 \%(2 / 2315)$ for category 2 patients and $.01 \%$ for category 3 patients $(1 / 8166)(p=<0.01)$.

\section{Consensual validity}

Consensual validity was assessed through an audit of triage records, principally focussed on compliance with SITS documentation requirements. Point estimates should be interpreted with a confidence interval of $+/-5 \%$ at a confidence level of $95 \%$.

Of 96 charts, $94(98 \%)$ had a triage time recorded and $86(90 \%)$ had a triage category assigned. Among the 46 paediatric charts, none had a MUAC performed. Additional data describing documentation compliance are displayed in Figure 4.

Reliability

For the 86 charts with a recorded triage category, inter-rater agreement was $88.4 \%$.

\section{Discussion}

SITS is the first purpose-designed triage system implemented in the Pacific region, and the only three-tier adaptation of the SATS. Notwithstanding the limitations of this evaluation, initial data suggests the scale has strong predictive validity (with significant differences in admission and fatality rates between triage categories) and adequate reliability ( $88.4 \%$ agreement). It is encouraging that, in the first three months of operation, 
$97.1 \%$ of patients had a triage category assigned and, at audit, $95 \%$ had a complete set of vital signs recorded at triage.

The results highlight many of the challenges of developing and delivering EC in RLEs. ${ }^{22}$ Incomplete data capture (eg, time of clinician assessment and disposition) is reflective of the workload in the ED, with clinicians prioritising clinical care over data recording. Similar experience has been reported in other resource-limited facilities implementing triage systems. ${ }^{23}$ Poor compliance with weight and MUAC screening for paediatric patients demonstrates that these functions are not a high priority for triage nurses. A relatively high proportion of patients are presenting for scheduled reviews and repeat prescriptions, highlighting challenges in access to primary care.

Consistent with experience in similar settings, ${ }^{14,24}$ the waiting times reported in this study illustrate that there are significant delays to care from the time of triage. Now that this data is available, it is being used to drive performance improvement within the ED.

These data appear to validate the decision to adopt a three-tier system over a more complex scale. Although several authors have suggested improved validity of five-tier scales, ${ }^{9,25}$ these studies have largely been conducted in developed settings and have limited generalisability to resource-limited EDs. More complex scales can lead to delays at triage because of the extra time required to assess and differentiate category three and four patients. ${ }^{25}$

The findings of this study are broadly consistent with the experience of other resource-limited EDs that have recently implemented triage scales. In Sierra Leone, the SATS proved a reliable tool that also led to improvements in waiting times for high acuity patients. ${ }^{13}$ Similarly, in Somaliland ${ }^{12}$ and rural South Africa, ${ }^{14}$ the SATS demonstrated feasibility as well as sound predictive validity. A recent review of the SATS in non-African 
settings found a significant correlation between triage category, admission rate and mortality, similar to the findings in this study. ${ }^{11}$

Lessons learned

The introduction of SITS has demonstrated that it is feasible to develop and implement a triage system in a low-resource setting within a relatively short timeframe. It has also highlighted some of the ancillary benefits of functional registration and data management systems. The number of recorded ED presentations, for example, nearly doubled after the implementation of the new ED database. This data is being used to advocate for resources.

Despite the overall positive findings, implementation of SITS was not without its challenges. These are highlighted in Table 1. Consistent with an action research approach, these reflections are being used to refine SITS and improve patient flow processes at NRH.

\section{Limitations}

There are several limitations to this study. Assessment of predictive validity relied on routinely collected data and surrogate measures, and disposition destination was absent for $25 \%$ of patients. Incomplete data may have resulted in under-reporting of admission and mortality rates.

No inferences can be drawn from this study about the impact on efficiency, morbidity and mortality. As there was no electronic ED database in operation prior to this intervention, baseline waiting times and clinical outcomes are unknown.

This article is protected by copyright. All rights reserved. 
The audit process applied in this study utilised a visiting nurse from Australia. It is possible that this may have resulted in improved compliance with triage documentation through the Hawthorne effect. In addition, interrater reliability was assessed with simple percent agreement, so the influence of chance has not been taken into account. The small sample size and limited timeframe also limits the interpretability.

In recognition of these limitations, a further evaluation is planned for 2019. This will reassess validity, calculate under- and over-triage rates against published standards and re-examine reliability using the kappa statistic for inter-rater agreement.

\section{Funding}

Funding for the volunteer nurse advisor position was provided by DFAT through the Solomon Islands Graduate Intern Support \& Supervision Project. The senior registrar position was facilitated by AVI under the auspices of the Australian Volunteers for International Development program.

\section{Conclusion}

SITS is the first purpose-designed, three-tier triage scale to be implemented in the Pacific region. This evaluation, conducted six months post-implementation, has demonstrated adequate predictive and consensual validity as well as acceptable reliability. New systems for patient flow and data management, implemented as part of the SITS process, are also helping to improve ED functioning and drive performance improvement. The partnership between Australian volunteers and local clinicians is a positive example of EC capacity building, and represents a model that could be implemented in other resource-limited settings.

\section{Acknowledgements}

This article is protected by copyright. All rights reserved. 
The authors acknowledge all the clinicians at NRH ED who contributed to the development and implementation of the SITS, and continue to work hard to deliver timely emergency care to Solomon Islanders. Special thanks go to Narrel Puia, NRH ED administration officer, for data entry and to the Australian Government for funding the Australian volunteer positions that were integral to this process.

\section{References}

1. World Bank. Solomon Islands [Internet]. [cited 2018 May 23];Available from: https://data.worldbank.org/country/solomon-islands

2. World Health Organization. Health Service Delivery Profile Solomon Islands 2012. Honiara: 2012.

3. United Nations Development Programme. Human Development Index.

4. Australasian College for Emergency Medicine. Report: Scoping Mission for Emergency Department Improvement Solomon Islands. Melbourne: 2014.

5. Anderson PD, Suter RE, Mulligan T, Bodiwala G, Razzak JA, Mock C. World Health Assembly Resolution 60.22 and its importance as a health care policy tool for improving emergency care access and availability globally. Ann Emerg Med 2012;60(1):35-44.e3.

6. Hsia R, Razzak J, Tsai AC, Hirshon JM. Placing emergency care on the global agenda. Ann Emerg Med 2010;56(2):142-9.

7. Razzak J, Kellermann AL. Emergency medical care in developing countries: is it worthwhile? Bull World Health Organ 2002;80(01):900-5.

8. Kobusingye OC, Hyder AA, Bishai D, Hicks ER, Mock C, Joshipura M. Emergency medical systems in lowand middle-income countries: recommendations for action. Bull World Health Organ 2005;83(8):626-

This article is protected by copyright. All rights reserved. 
31.

9. FitzGerald G, Jelinek GA, Scott D, Gerdtz MF. Emergency department triage revisited. Emerg Med J 2010;27(2):86-92.

10. Jenson A, Hansoti B, Rothman R, de Ramirez SS, Lobner K, Wallis L. Reliability and validity of emergency department triage tools in low- and middle-income countries: a systematic review. Eur J Emerg Med 2018;25(3):154-60.

11. Dalwai M, Valles P, Twomey M, et al. Is the South African Triage Scale valid for use in Afghanistan, Haiti and Sierra Leone? BMJ Glob Heal 2017;2(2):e000160.

12. Sunyoto $\mathrm{T}$, Van Den Bergh $\mathrm{R}$, Valles $\mathrm{P}$, et al. Providing emergency care and assessing a patient triage system in a referral hospital in Somaliland: A cross-sectional study. BMC Health Serv Res 2014;14(1).

13. Lowsby R, Kamara C, Kamara M, et al. An assessment of nurse-led triage at Connaught Hospital, Sierra Leone in the immediate post-Ebola period. African J Emerg Med 2017;7(2):51-5.

14. Meyer GD, Meyer TN, Gaunt CB. Validity of the South African Triage Scale in a rural district hospital. African J Emerg Med 2018;(May):0-1.

15. Dalwai MK, Twomey M, Maikere J, et al. Reliability and accuracy of the South African triage scale when used by nurses in the emergency department of Timergara hospital, Pakistan. South African Med J 2014;104(5):372-5.

16. Twomey M, Cheema B, Buys $\mathrm{H}$, et al. Vital signs for children at triage: A multicentre validation of the revised South African triage scale (SATS) for children. South African Med J 2013;103(5):304-8.

17. Rominski S, Bell SA, Oduro G, Ampong P, Oteng R, Donkor P. The implementation of the South African Triage Score (SATS) in an urban teaching hospital, Ghana. African J Emerg Med 2014;4(2):71-5.

This article is protected by copyright. All rights reserved. 
18. Molyneux E, Ahmad S, Robertson A. Improved triage and emergency care for children reduces inpatient mortality in a resource-constrained setting. Bull World Health Organ 2006;84(4):314-9.

19. Koshy E, Koshy V, Waterman H. Action Research in Healthcare. London: SAGE; 2011.

20. de Magalhães-Barbosa MC, Robaina JR, Prata-Barbosa A, Lopes C de S. Validity of triage systems for paediatric emergency care: a systematic review. Emerg Med J 2017;34(11):711-9.

21. Twomey M, Wallis LA, Myers JE. Limitations in validating emergency department triage scales. Emerg Med J 2007;24(7):477-9.

22. Obermeyer Z, Abujaber S, Makar M, et al. Emergency care in 59 low- and middle-income countries: a systematic review. Bull World Health Organ 2015;93(8):577-586G.

23. Abdelwahab R, Yang $\mathrm{H}$, Teka HG. A quality improvement study of the emergency centre triage in a tertiary teaching hospital in northern Ethiopia. African J Emerg Med 2017;7(4):160-6.

24. Bruijns SR, Wallis LA, Burch VC. Effect of introduction of nurse triage on waiting times in a South African emergency department. Emerg Med J 2008;25(7):395-7.

25. Health Policy Priorities Principal Committee. Australian triage process review - report. Adelaide: 2011. 
Table 1: Challenges faced during the development and implementation of the SITS

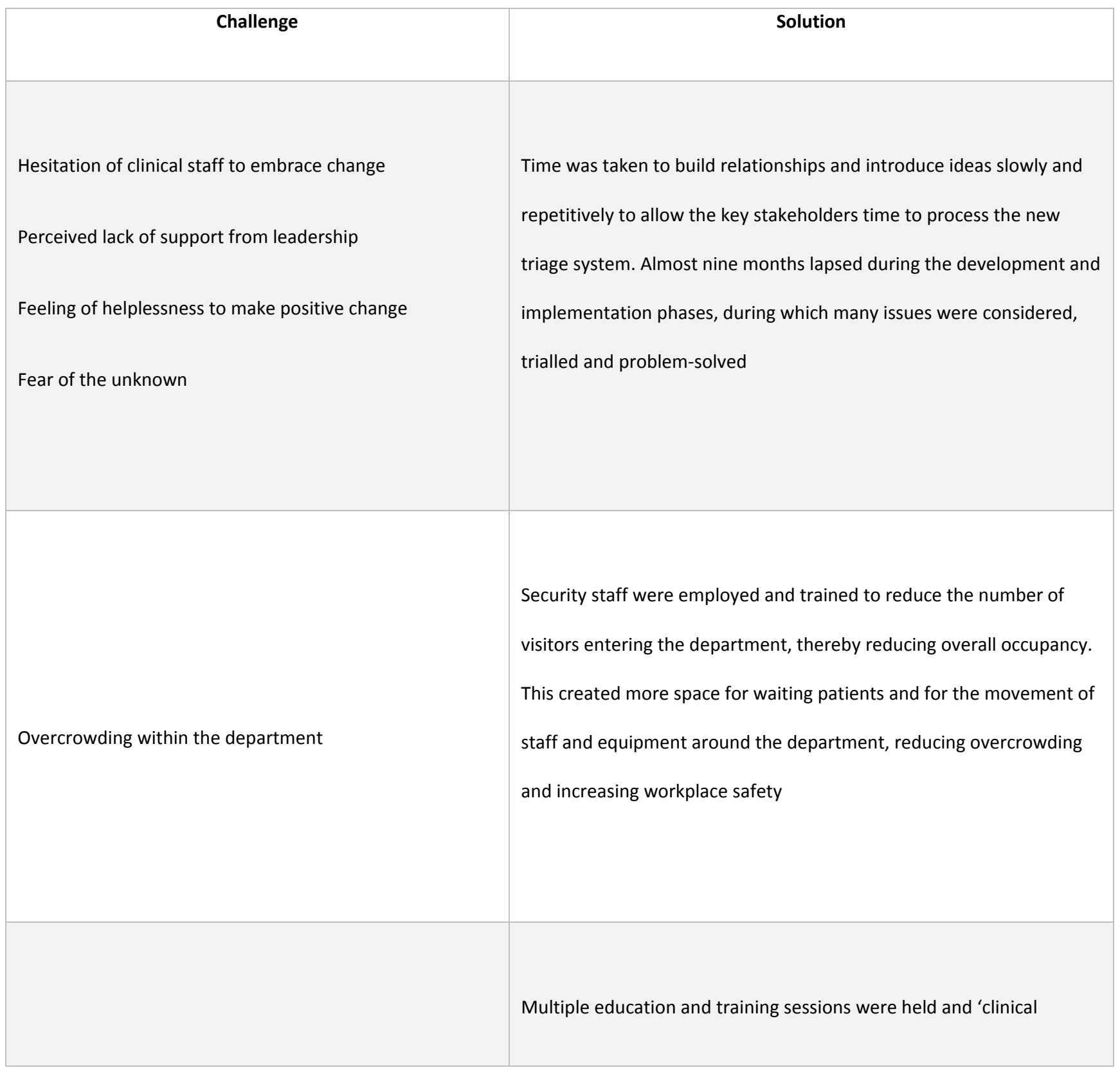


Lack of assessment equipment for accurate physiological measurement and recording of vital signs, including (but not limited to) sphygmomanometers, stethoscopes, fingertip pulse oximeters, thermometers, blood glucose testing kits, glass malaria slides, sharps containers, waste bins, pen torches and weighing scales

Lack of a designated and safe area to triage patients
External fundraising allowed for nursing kits to be provided for all emergency staff at a minimal cost, allowing staff to maintain responsibility for their own equipment and ensure availability for use within the ED

A custom designed triage assessment area was built on the verandah using donated funds. This improved patient privacy during triage assessment of patients and facilitated safe storage of equipment

A standalone hand washing station was designed and built to enable

Lack of handwashing facilities in triage area 
Flow charts depicting several alternate pathways were developed, discussed and trialled to assess the most effective solution in the physical workspace.

Ineffective flow of patients through the department

A whole of hospital approach was adopted. The importance of timely admission and ward transfer was emphasised to inpatient units.

Beds for short stay patients were quarantined

Old medical records were removed and stored elsewhere to free up an assessment room

Limited assessment rooms within the department for assessing and treating category 3 patients

Curtains were hung in another area to improve patient privacy and create an additional assessment environment

Excessive equipment and poor layout of paediatric ward resulting in unsafe access to patients in an emergency
The paediatric area was reorganised to allow for better visibility of patients 
Figure Legend:

Figure 1 Patient Flow Pathway

Figure 2a SITS flow chart

Figure $2 \mathrm{~b}$ SiTS paediatric flow chart

Figure 3: Admission rates by triage category

Figure 4 Compliance with triage documentation

This article is protected by copyright. All rights reserved. 
Figure 3: Admission rates by triage category

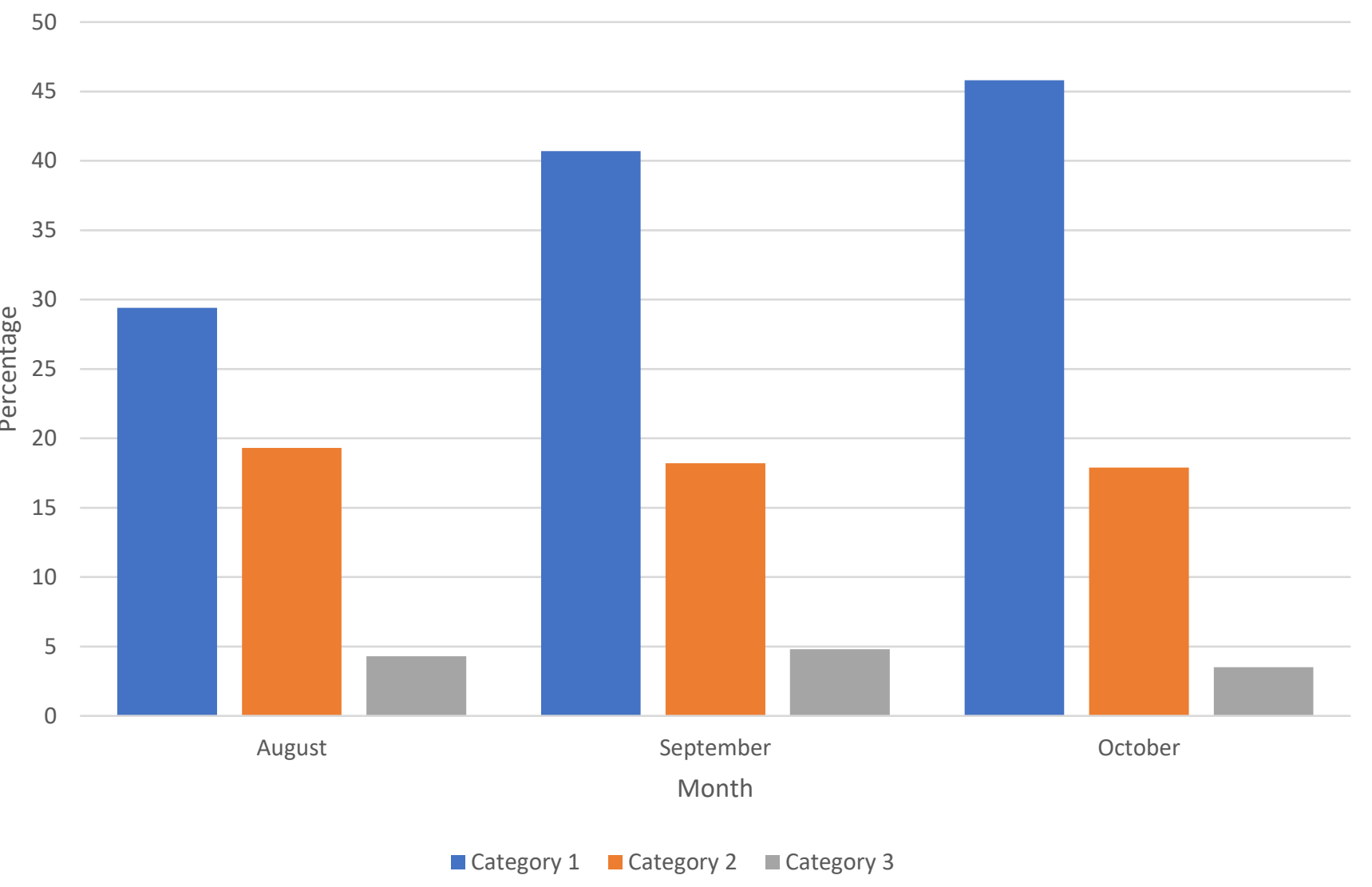

This article is protected by copyright. All rights reserved. 
Table 1: Challenges faced during the development and implementation of the SITS

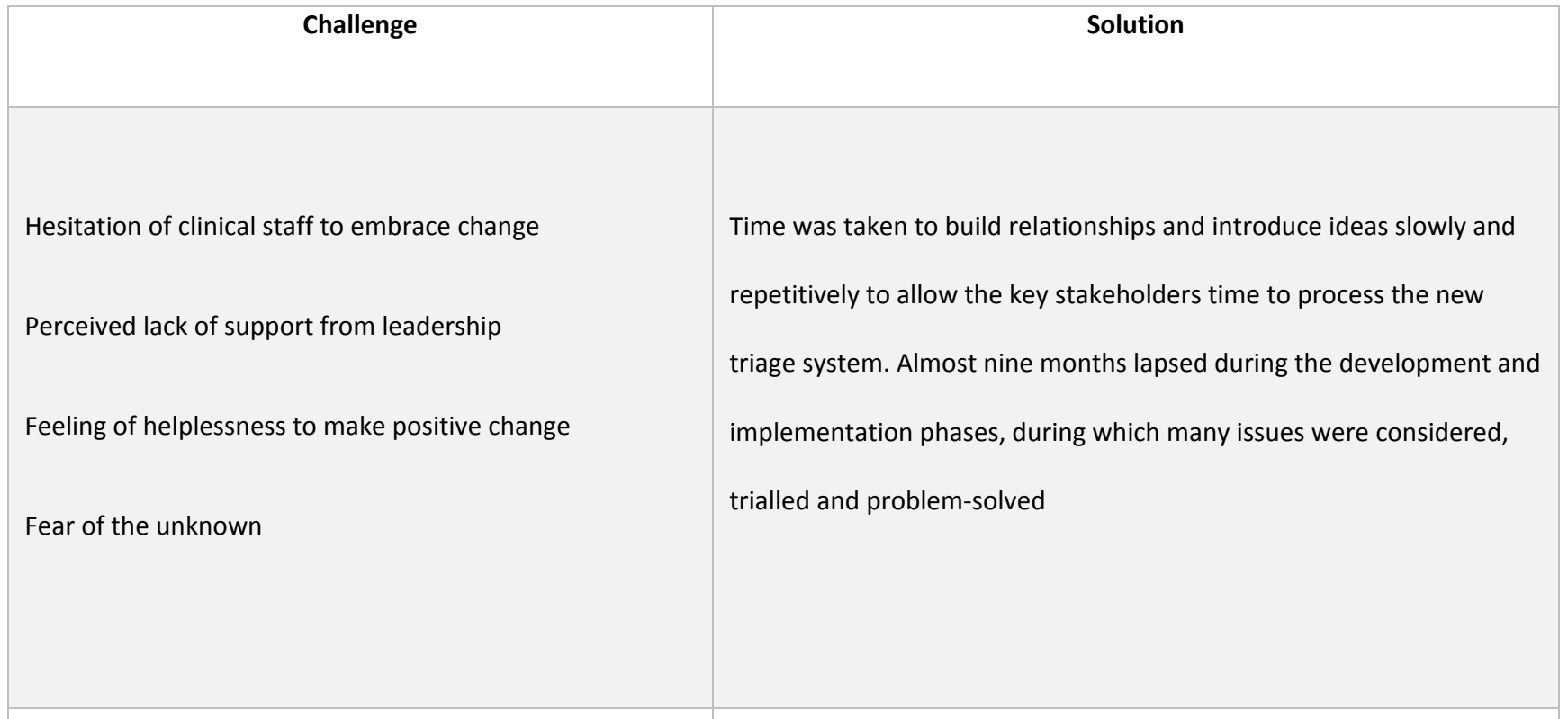

Security staff were employed and trained to reduce the number of visitors entering the department, thereby reducing overall occupancy. This created more space for waiting patients and for the movement of staff and equipment around the department, reducing overcrowding and increasing workplace safety

Multiple education and training sessions were held and 'clinical champions' were identified to provide real-time support. Training increased confidence, and staff were all encouraged to give feedback

Lack of confidence among staff (which was noted and acted on)

Lack of assessment equipment for accurate physiological measurement and recording of vital signs, including (but
External fundraising allowed for nursing kits to be provided for all emergency staff at a minimal cost, allowing staff to maintain 
not limited to) sphygmomanometers, stethoscopes,

fingertip pulse oximeters, thermometers, blood glucose

testing kits, glass malaria slides, sharps containers, waste

bins, pen torches and weighing scales

Lack of a designated and safe area to triage patients

Lack of handwashing facilities in triage area

Ineffective flow of patients through the department responsibility for their own equipment and ensure availability for use within the ED

A custom designed triage assessment area was built on the verandah using donated funds. This improved patient privacy during triage assessment of patients and facilitated safe storage of equipment

A standalone hand washing station was designed and built to enable staff to practice effective hand hygiene between patients

Flow charts depicting several alternate pathways were developed, discussed and trialled to assess the most effective solution in the physical workspace.

A whole of hospital approach was adopted. The importance of timely admission and ward transfer was emphasised to inpatient units.

Beds for short stay patients were quarantined 
Old medical records were removed and stored elsewhere to free up an assessment room.

Limited assessment rooms within the department for assessing and treating category 3 patients

Curtains were hung in another area to improve patient privacy and

create an additional assessment environment

Excessive equipment and poor layout of paediatric ward

The paediatric area was reorganised to allow for better visibility of resulting in unsafe access to patients in an emergency patients 
Figure 4: Compliance with triage documentation requirements

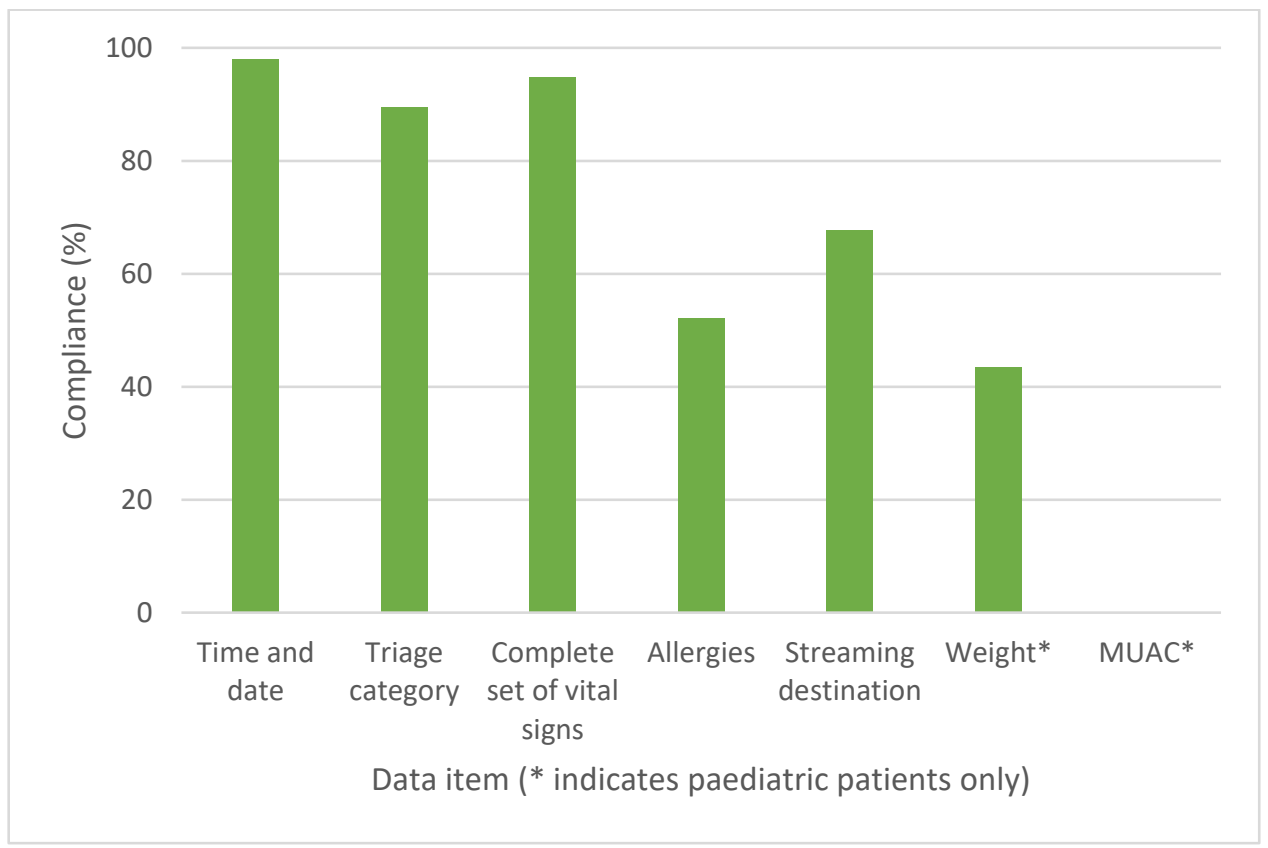

This article is protected by copyright. All rights reserved. 


\section{ED PATIENT FLOW PATHWAY FROM TRIAGE}

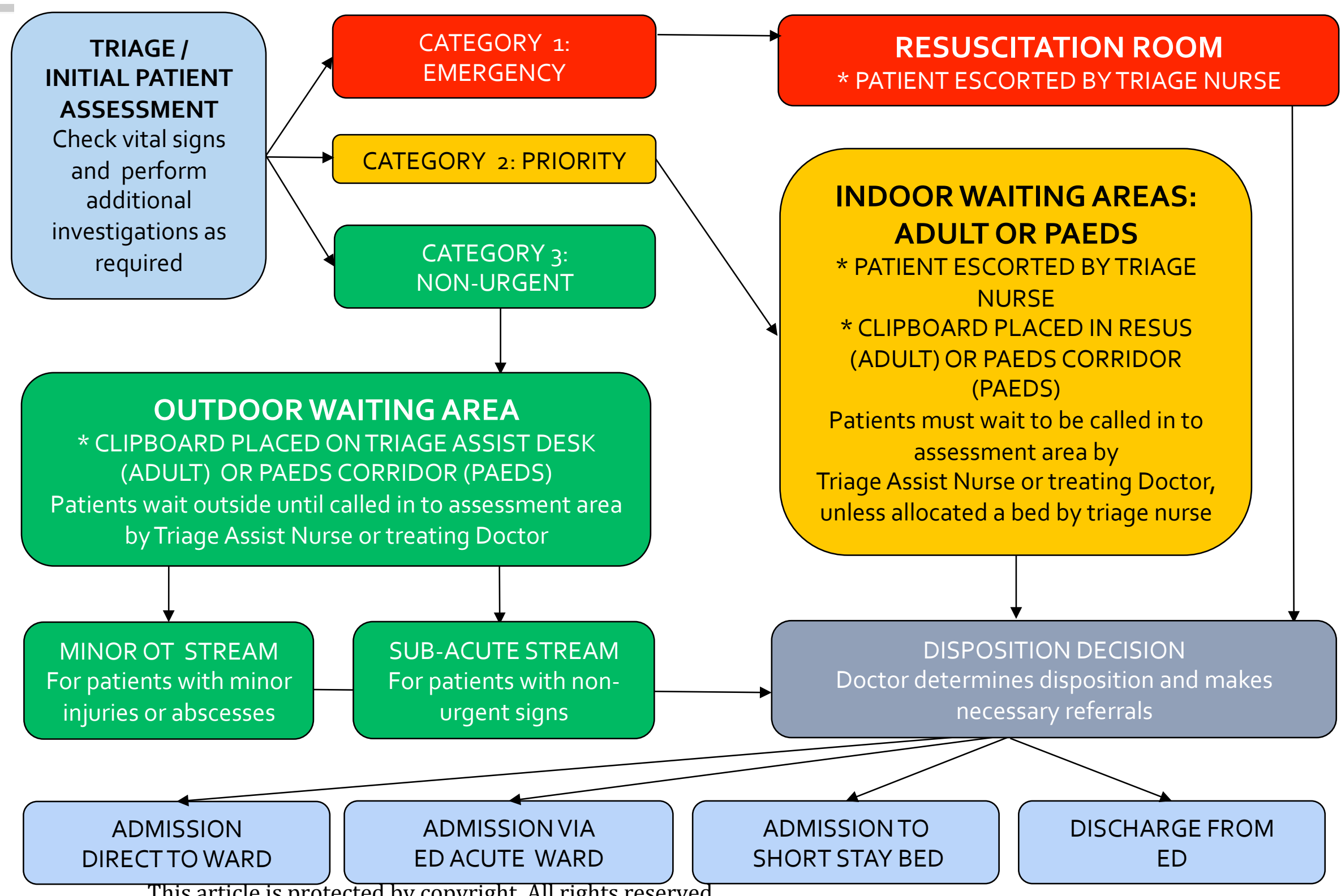

This article is protected by copyright. All rights reserved. 


\section{ADULT Solomon Islands Triage Scale}

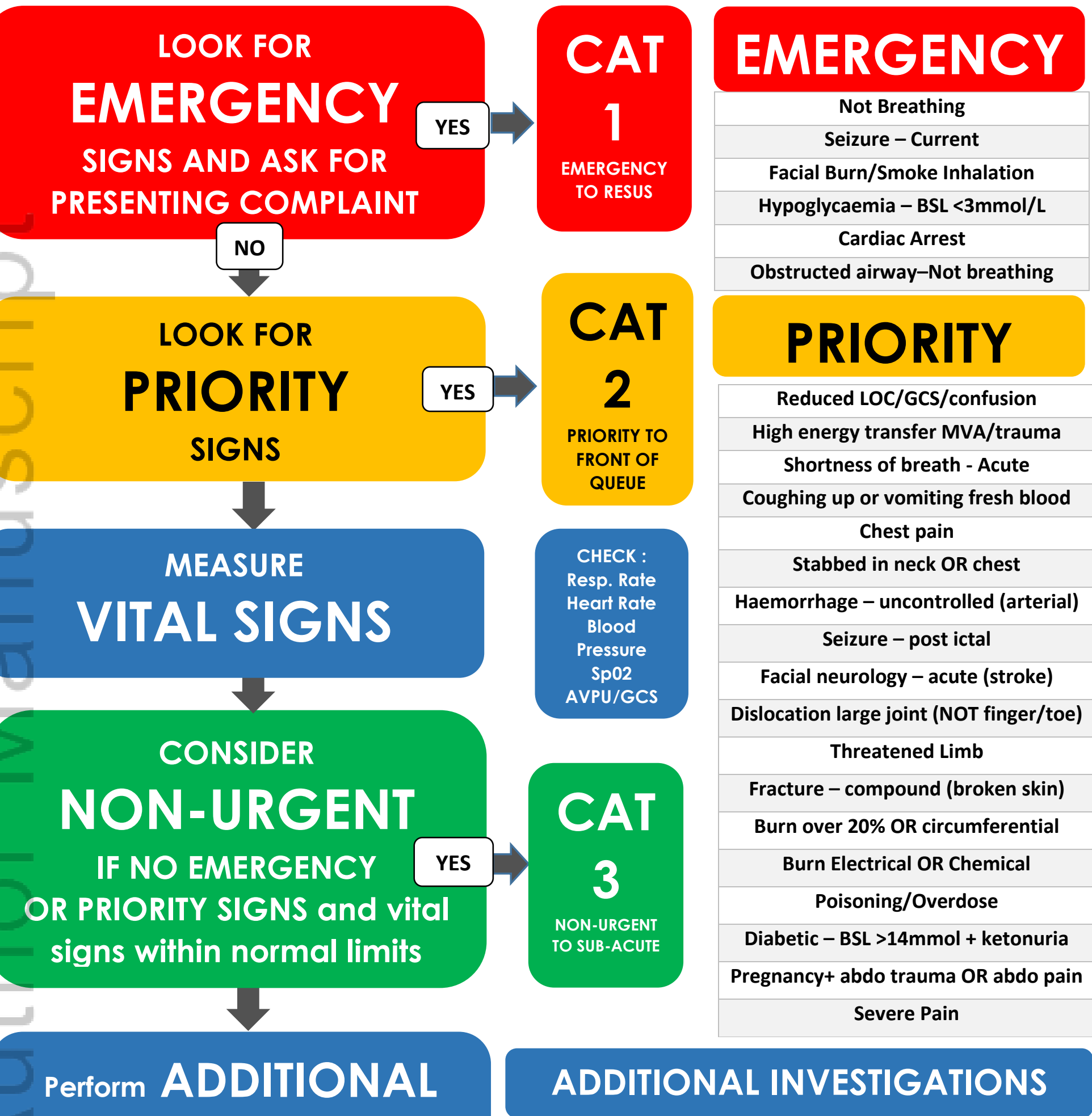

\section{INVESTIGATIONS}

\section{(As required)}

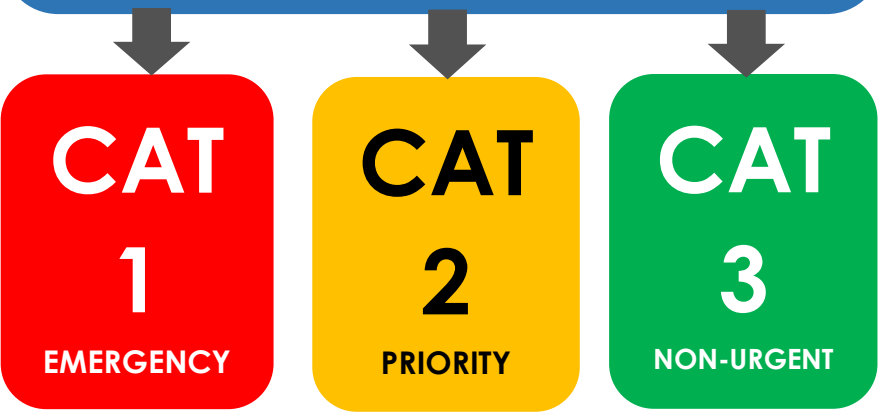

\section{ADDITIONAL INVESTIGATIONS}

\section{SIGNS}

Acute respiratory distress

Reduced LOC/GCS/AVPU

OR history of diabetes

Diabetes + Hyperglycaemia

(glucose $11 \mathrm{mmol} / \mathrm{L}$ or more)

Can't sit up/needs to lie down

Chest pain

Active seizure/fitting

Acute abdominal pain

or backache, female

\section{ACTION}

Check Sp02, hand over to resus to administer 02

Do a finger prick glucose test

If $B S L<3 \mathrm{mmol}$, give food/drink

Urine dipstick to check for ketones, if yes,

resus

Do a finger prick glucose test

Immediate ECG in resus; return to waiting

room only if ECG normal + reviewed by MO

IV access, hand over to resus

Urine dipstick and urine pregnancy test

Adapted From The South African Triage Scale Training Manulal 2012, West Cape Government Health 


\section{PAEDIATRIC Solomon Islands Triage Scale}

LOOK FOR

EMERGENCY

SIGNS AND ASK FOR

PRESENTING COMPLAINT

\section{No}

$\checkmark$

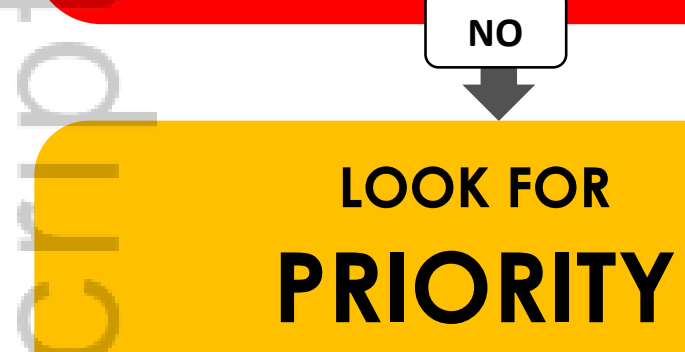

SIGNS

$\checkmark$

\section{MEASURE}

VITAL SIGNS

\section{CONSIDER}

NON-URGENT

IF NO EMERGENCY

OR PRIORITY SIGNS

\& vital signs within normal limits

FOR AGE OF CHILD $\rightarrow \Delta$

\section{YES}

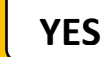

Resp. Rate

Heart Rate

Sp02/WOB

AVPU/GCS

BSL (as

indicated)

Pain Level

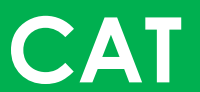

3

NON-URGENT to SUB-ACUTE

\section{EMERGENCY}

Airway obstructed/Not Breathing:

- Central Cyanosis or

- Severe Respiratory Distress

Cold hands with ANY of:

- Capillary refill >3 seconds

- Weak and fast pulse

- Slow $(<60 \mathrm{bpm})$ or absent pulse

Coma/Convulsing/Confusion/AVPU=P or $\mathrm{U}$

Diarrhoea with sunken eyes/

return of skin pinch $\geq 2$ secs

\section{PLEASE WEIGH ALL CHILDREN}

\section{PRIORITY}

Tiny - sick infant aged $<2$ months

Temperature - very high $>39.5^{\circ} \mathrm{C}$

Trauma - major trauma/MVA

Pain - child in severe pain

Poisoning - Mother reports poisoning

Pallour - severe palmar pallour

Restless/Irritable/Floppy

Respiratory distress

Referral - has an URGENT referral letter

Malnutrition - visible severe wasting

Oedema of both feet

Burns - severe burns

\section{Perform ADDITIONAL INVESTIGATIONS}

\section{(As required)}

\section{$+\zeta$}

$\rightarrow \Delta$

4

EMERGENCY
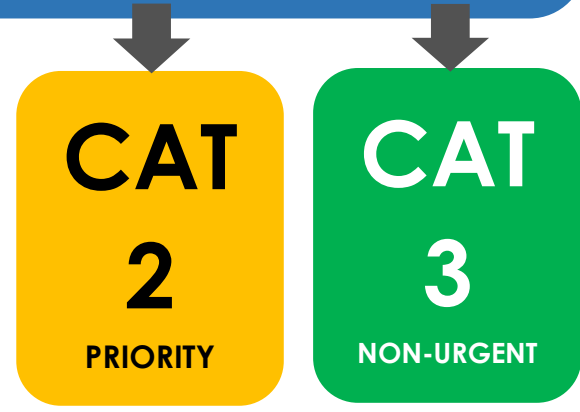

\section{ADDITIONAL INVESTIGATIONS}

\section{SIGNS}

Acute respiratory distress

Reduced LOC/GCS/AVPU

OR history of diabetes

Diabetes + Hyperglycaemia

(glucose $11 \mathrm{mmol} / \mathrm{L}$ or more)

Can't sit up/needs to lie down

Severe dehydration

Active seizure/fitting

Fever plus purpuric rash

Active Bleeding

\section{ACTION}

Check Sp02, hand over to resus for 02

Do a finger prick glucose test

If $\mathrm{BSL}<3 \mathrm{mmol}$, give food/drink

Urine dipstick to check for ketones, if yes,

resus

Do a finger prick glucose test

IV access or IO, oral rehydration if possible

IV access, hand over to resus

Isolate and alert senior medical staff

Assess for excessive blood loss,

apply pressure to wound

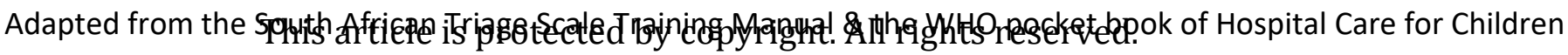




\section{University Library}

\section{- M M N E R VA A gateway to Melbourne's research publications}

Minerva Access is the Institutional Repository of The University of Melbourne

Author/s:

Wanefalea, LE;Mitchell, R;Sale, T;Sanau, E;Phillips, GA

Title:

Effective triage in the Pacific region: The development and implementation of the Solomon Islands Triage Scale

Date:

2019-06-01

Citation:

Wanefalea, L. E., Mitchell, R., Sale, T., Sanau, E. \& Phillips, G. A. (2019). Effective triage in the Pacific region: The development and implementation of the Solomon Islands Triage Scale. EMERGENCY MEDICINE AUSTRALASIA, 31 (3), pp.451-458. https:// doi.org/10.1111/1742-6723.13248.

Persistent Link:

http://hdl.handle.net/11343/285580 